\title{
Regulasi Emosi dan Aggressive Driving Behavior Siswa
}

\author{
Citra Marhan', Waode Suarni², Yuliastri Ambar Pambudhi ${ }^{3}$, \& Nur Qalbih ${ }^{4}$ \\ Jurusan Psikologi \\ Fakultas Keguruan Dan IImu Pendidikan, Universitas Halu Oleo \\ chetramarhan02@gmail.com¹, waodesuarni@yahoo.com ${ }^{2}$, yul psy@yahoo.com³ \\ nur.qalbih1011@gmail.com ${ }^{4}$
}

\begin{abstract}
Abstrak : Aggressive driving behavior merupakan perilaku mengemudi yang disfungsional dan mengganggu keamanan publik. Pengendara yang berperilaku agresif dalam berkendara dikarenakan mereka mengendara dibawah pengaruh emosi yang tidak stabil. Penelitian ini bertujuan untuk mengetahui hubungan antara regulasi emosi dan aggressive driving behavior pada siswa SMK Negeri 2 Kendari. Jenis penelitian ini yaitu kuantitatif dengan desain korelasional. Subjek dalam penelitian ini adalah 90 siswa laki-laki SMK Negeri 2 Kendari yang mengendarai sepeda motor dengan kisaran usia 14-18 tahun. Instrumen dalam penelitian ini menggunakan skala regulasi emosi dan skala aggressive driving behavior. Teknik analisis data menggunakan formula korelasi Product Moment Pearson dengan menggunakan SPSS versi 20.0. Hasil uji statistik menunjukkan bahwa regulasi emosi dengan kategori sedang sebanyak 66,67\%, sedangkan aggressive driving behavior dengan kategori sedang sebanyak $62,22 \%$ dengan koefisien korelasi yang diperoleh sebesar 0,464 dengan taraf signifikansi 0,000 . Nilai korelasi yang diperoleh bertanda positif menunjukkan bahwa ada hubungan positif yang signifikan antara regulasi emosi dan aggressive driving behavior pada siswa SMK Negeri 2 Kendari, maka hipotesis dalam penelitian ini ditolak.
\end{abstract}

Kata kunci : aggressive driving behavior ; regulasi emosi ; siswa

\begin{abstract}
Agressive driving behavior is notorically dysfunctional disrupted public security. Drivers who behave aggressively in driving because they ride under unstable emotional influence. The purpose of this research is to know about the relationship between emotional regulation and Agresive Driving Behavior of students in SMKN 2 KENDARI. The type of the research is quantitative study with correlation design. The subject of this research is 90 males' students of SMKN 2 KENDARI who ride motorcycles. The instrument in this research use the emotional regulatory and the Aggressive Driving Behavior scale. The data analysis technique uses product moment correlation formula Pearson using a 20.0 version SPSS. Statistic test relevealed that the moderate emotional regulation of $66.67 \%$, while Aggressive Driving Behavior is at $62.22 \%$ with 0.464 with coefficient correlation obtained by 0.464 with degree of significance of 0.000. The value of marked positive correlation indicates that there is significant positive connection between emotional regulation and Aggressive Driving Behavior of students in SMKN 2 Kendari, so the hypothesis of this research being denied.
\end{abstract}

Keywords : agressive driving behavior ; emotion regulation ; students 


\section{Pendahuluan}

Fenomena aggressive driving behavior atau perilaku mengendara yang agresif pada pengendara sepeda motor dapat terlihat dalam kondisi yang padat dan sesak, seperti yang terjadi pada pagi hari saat berangkat sekolah atau kerja atau sore hari saat pulang. Biasanya perilaku agresif yang ditunjukkan di saat kondisi padat dan sesak tersebut adalah mengemudi dengan jarak terlalu dekat dengan kendaraan lain atau menyalip dan menyerobot kendaraan lain yang ada di depannya. Terkadang perilaku mengemudi seperti ini dapat menimbulkan kecelakaan kecil seperti menyerempet kendaraan lain. Apabila hal ini terjadi, biasanya perilaku agresif yang muncul adalah mengumpat, mengklakson, bahkan terkadang sampai menimbulkan perselisihan di antara para pengendara. Perilaku seperti ini disebutkan oleh Harris, Houston, Vazquez, Smither, dan Harms (2014) merupakan perilaku yang menimbulkan respon konflik.

Aggressive driving behavior bisa dilakukan oleh siapa saja yang mengendara, termasuk siswa yang berusia remaja. Masa remaja merupakan masa peralihan dari masa kanak-kanak menuju masa dewasa yang berlangsung antara usia 10-19 tahun. Masa remaja sebagai salah satu tahap perkembangan kehidupan yang dilewati oleh setiap individu. Masa remaja merupakan masa yang cukup sulit, karena pada masa ini akan terjadi differentiation failure atau ketidakmampuan remaja dalam membedakan apa yang menjadi keyakinan dirinya dan orang lain. Selain itu, pada masa ini juga para remaja sedang mengalami fase strom and stress serta masa pencarian identitas (Santrock, 2011).

Remaja yang berada pada tahap pencarian identitas ini memiliki energi yang besar dan berlebih sehingga menyebabkan mereka terus mencoba hal yang dianggap baru. Tidak jarang pula remaja melakukan hal-hal yang negatif, misalnya berperilaku agresif (Swadnyana \& Tobing, 2019). Salah satu bentuk perilaku agresif yang sering diperlihatkan remaja saat di jalan raya adalah mengendara dengan agresif. Komponen perilaku mengendara yang agresif menurut Collado (Herani \& Jauhari, 2017) diantaranya adalah speeding atau mengebut, tailgating yaitu membuntuti kendaraan lain yang berada di depannya dengan jarak yang sangat dekat, the accordion effect yaitu tidak memberikan kesempatan kepada pengendara lain untuk memotong masuk, fast drivers bentuk perilaku agresif mengemudi yang banyak mengambil resiko hanya untuk menghindari kemacetan, dan emotional influence yaitu pengaruh emosi dari pengendara itu sendiri.

Pada penelitian yang dilakukan Rakhmani (2013) didapatkan hasil bahwa remaja berpikir mereka cukup dewasa untuk mengendara sepeda motor di jalan, tetapi dengan pengetahuan tentang mengemudi yang dangkal sering menyebabkan kecelakaan fatal. Pengetahuan mereka tentang kendaraan masih kurang karena masih merupakan hal baru bagi mereka. Kurangnya pengetahuan dan pengalaman tersebut membuat pengemudi remaja kurang tanggap terhadap situasi yang membahayakan sehingga berpotensi terjadinya kecelakaan di jalan raya. Kustiyah (2011) mengatakan bahwa pengetahuan tentang rambu lalu lintas pada pengendara juga berpengaruh terhadap terjadinya kecelakaan lalu lintas.

Pengemudi, yang juga merupakan pengguna jalan memerlukan pengetahuan dan keterampilan dalam mengemudikan kendaraan bermotor agar dapat menjaga keselamatan dalam berkendara. Pengemudi dengan pengalaman yang minim dan kurangnya keterampilan dalam mengemudi dengan aman beresiko tinggi untuk mengalami kecelakaan lalu lintas dan cedera (Hidayati, 2015). Menurut Permanawati, Sulistio, \& Wicaksono (2010) peluang terjadinya kecelakaan lalu lintas disebabkan karena kurangnya pengetahuan seseorang dalam berkendara seperti arti lalu lintas, bahaya apabila melanggar peraturan lalu lintas dan 
sebagainya. Notosiswoyo (2014) juga menyebutkan bahwa pengetahuan dan sikap memiliki pengaruh sebesar 3\% terhadap perilaku seseorang dalam upaya pencegahan kecelakaan.

Peneliti melakukan wawancara awal pada siswa SMK Negeri 2 Kendari pada tanggal 20 Agustus 2019, diperoleh informasi bahwa dua siswa mengatakan apabila ada teman yang mengajak ngebut, subjek akan menambah kecepatan motornya, terlebih lagi apabila saat cuaca panas. Saat kondisi jalanan macet biasanya subjek mengendara dengan jarak dekat, serta menyalip dengan pengendara motor lain karena terburu-buru dan subjek merasa senang, serta tetap santai apabila menjadi pusat perhatian. Empat siswa mengaku mengendarai motor dengan kecepatan tinggi atau ngebut apabila ada urusan yang mendesak, terburu-buru agar tidak terlambat ke sekolah, dan untuk menghemat waktu, sedangkan dua siswa lainnya mengaku mengendarai motor dengan kecepatan tinggi di jalan tertentu saja dan apabila jalanan sedang sepi, namun tetap mengutamakan keselamatan.

Pengendara perempuan maupun laki-laki juga dapat melakukan aggressive driving. Menrut penelitian yang dilakukan oleh Holland, Geraghty, dan Shah (2010) dengan 222 responden laki-laki dan perempuan usia muda, ditemukan bahwa subjek laki-laki lebih memunculkan gaya mengemudi yang beresiko, serta mengendara dengan kecepatan tinggi dan mudah marah sehingga sangat rentan dengan munculnya perilaku berkendara yang agresif dan beresiko. Penelitian lain oleh Ambarwati, Sulistio, Negara, \& Hariadi (2010) mengatakan bahwa pengendara pada rentang usia 17-24 tahun menunjukkan agresif dalam mengendara yang tinggi sehingga sering mengakibatkan ketidakdisiplinan berujung pada kecelakaan.

Haleem dan Gan (2015) menyatakan bahwa aggressive driving behavior telah diidentifikasi sebagai faktor yang signifikan dalam kecelakaan lalu lintas. Di Amerika Serikat, pada tahun 2014 ada enam juta kecelakaan dilaporkan ke polisi yang melibatkan 37.641 kematian. Dari kecelakaan tersebut diketahui $55 \%$ disebabkan oleh perilaku mengemudi yang agresif atau aggressive driving behavior. Angka kecelakaan lalu lintas di Indonesia merupakan salah satu dari sepuluh Negara yang memiliki angka terbesar di dunia dari total kecelakaan di dunia (World Health Organization, 2013). Data lain dari Kepolisian Republik Indonesia, fatalitas kecelakaan Lalu Lintas Angkutan Jalan (LLAJ) bahwa pada tahun 2016 terdapat 25.869 jiwa korban kecelakaan. Angka ini meningkat dari tahun sebelumnya sebesar 24.336 jiwa korban kecelakaan di jalan raya (Anggar, 2017). Sedangkan di Kota Kendari sendiri jumlah kecelakaan pada tahun 2018 adalah 260 kejadian.

Emosi merupakan aspek yang dapat mempengaruhi perilaku seseorang, demikian juga saat berkendara. Ketidakmampuan pengendara untuk mengontrol emosinya saat mengendara membuat pengendara cenderung melampiaskannya pada saat di jalan.

Berbagai emosi yang dirasakan saat berkendara dapat dikelola dan diatur. Pengaturan dan pengelolaan emosi tersebut disebut regulasi emosi. Gross dan Thompson (2007) menjelaskan bahwa regulasi emosi adalah sekumpulan berbagai proses tempat emosi diatur atau dikelola. Individu yang dapat mengatasi masalah yang dihadapi, mampu mengontrol emosi yang dirasakan, tidak terpengaruh dengan emosi negatif, dan tidak merasa malu karena merasakan emosi negatif tersebut merupakan aspek regulasi emosi menurut Gross dan Thompson (2007).

Trogolo, Melchior dan Medrano (2014) menjelaskan bahwa pengendara yang tidak dapat mengatur dan mengendalikan emosi negatif yang dirasakan mempunyai kecenderungan untuk berperilaku agresif dalam berkendara yang berakibat buruk bagi 
dirinya dan pengguna jalan lain, sebaliknya pengendara yang memiliki kemampuan mengatur emosi akan mengemudi dengan hati-hati. Emosi negatif dapat membentuk perilaku berkendara yang tidak aman dan berujung pada kecelakaan. Arnau-Sabates, SalaRoca, \& Joriat-Garcia (2012) menemukan bahwa sikap yang cenderung beresiko atau berbahaya mempunyai hubungan negatif dengan kemampuan emosional. Hasil penelitiannya menunjukkan bahwa kemampuan emosional merupakan salah satu upaya pencegahan yang penting untuk mengurangi risky driving behavior dan aggressive driving behavior. Kesulitan meregulasi emosi merupakan salah satu kemampuan mengendalikan emosi. Menurut Ibraheim, Kalpakci \& Sharp (2017), kesulitan meregulasi secara umum diartikan sebagai seberapa sering dan seberapa intens pengalaman dari kombinasi emosi dengan ketidakmampuan mengatasi masalah yang terjadi.

Siswa SMK yang masih dalam usia remaja tahap akhir memiliki emosi yang belum matang dan kontrol diri yang masih labil, sehingga dengan berbagai keadaan dan suasana jalanan yang kurang kondusif misalnya kemacetan memungkinkan mereka untuk melakukan aggressive driving. Perilaku mengendara yang seperti ini dapat menyebabkan kecelakaan. Soffania (2018), siswa yang memiliki aggressive driving yang tinggi lebih banyak mengalami kecelakaan lalu lintas daripada siswa yang memiliki aggressive driving rendah.

Penelitian yang dilakukan Utari (2016) adalah hubungan antara aggressive driving dan kematangan emosi dengan disiplin berlalu lintas pada remaja. Kedisiplinan remaja dalam berlalu lintas banyak dipengaruhi oleh faktor kematangan emosi remaja itu sendiri. Hal ini mengakibatkan remaja melampiaskan rasa emosionalnya dengan cara berperilaku aggressive driving di jalan dengan berkendara ugal-ugalan atau mengikuti balap liar di jalan raya. Apabila kematangan emosi seorang remaja sesuai dengan usianya, maka remaja akan cenderung berperilaku sesuai dengan norma atau aturan yang berlaku termasuk dalam aturan disiplin berlalu lintas. Selain itu, pada penelitian Prasetyo dan Septiningsih (2011) yang mengungkapkan bahwa terdapat agresivitas dalam berkendara di jalan raya pada semua peserta didik berusia sekitar 16-18 tahun yang merupakan pengendara berusia muda. Aggressive driving pengendara berusia muda lebih mengarah ke bentukbentuk pelanggaran lalu lintas yang berdampak pada kecelakaan.

Dampak lain dari aggressive driving behavior selain kecelakaan adalah kerusakan properti serta kerugian material yang cukup besar. Berdasarkan uraian di atas, peneliti tertarik untuk melakukan penelitian tentang "hubungan antara regulasi emosi dan aggressive driving behavior pada siswa SMK Negeri 2 Kendari".

Penelitian ini memiliki tujuan untuk mengetahui hubungan antara regulasi emosi dan dan aggressive driving behavior pada siswa SMK Negeri 2 Kendari.

Manfaat dari penelitian ini diharapkan dapat memberikan sumbangan untuk ilmu pengetahuan psikologi khususnya untuk psikologi sosial dan psikologi klinis. Hasil dari penelitian ini juga diharapkan dapat memberi masukan kepada peneliti selanjutnya yang meneliti hal-hal yang berkaitan dengan regulasi emosi dan aggressive driving behavior.

\section{Metode Penelitian}

Penelitian ini menggunakan metode kuantitatif dengan desain korelasional. Sampel dalam penelitian ini adalah siswa SMK Negeri 2 Kendari yang dipilih berdasarkan teknik proportional random sampling. Instrumen pengumpulan data yang digunakan adalah skala regulasi emosi dan skala aggressive driving behavior. Definisi operasional mengenai variabel penelitian ini adalah regulasi 
emosi merupakan pengaturan atau pengelolaan emosi oleh siswa SMK Negeri 2 Kendari yang mengendara sepeda motor sehingga siswa mampu mengurangi kemarahan dan kesedihan yang dirasakan, tidak terpengaruh untuk marah atau gelisah, mampu mengontrol emosi saat mengendara dan tidak merasa malu karena ia bersedih dan kecewa. Aggressive driving behavior merupakan perilaku agresif siswa SMK Negeri 2 Kendari dalam mengemudi sepeda motor karena pengaruh emosi yang tidak stabil dan dapat membahayakan dirinya sendiri sebagai pengemudi, orang lain sebagai penumpang serta pengguna jalan lain baik secara fisik maupun mental yang dilakukan dengan sengaja, seperti membuntuti pengendara lain dengan jarak dekat, membunyikan klakson berulang kali, memberi isyarat kasar kepada pengendara lain, dan mengendara dengan kecepatan tinggi atau ngebut.

Analisis data yang digunakan dalam penelitian ini yaitu analisis deskriptif, yaitu untuk memberikan deskripsi mengenai data dari variabel yang diukur dan analisis data inverensial. Untuk mengetahui apakah data terdistribusi secara normal yakni menggunakan teknik Kolmograv Smirnov, dan apakah data dalam penelitian ini berhubungan secara linear dengan menggunakan test from linearity, serta pengujian hipotesis menggunakan teknik Korelasi Product Moment Pearson.

\section{Hasil Penelitian dan Pembahasan}

Pada tabel di bawah ini dapat diketahui bahwa sampel penelitian berjumlah 90 orang. Pada variabel regulasi emosi diketahui nilai Minimum yang diperoleh sama dengan 59, nilai Maxsimum sama dengan 90, dengan Mean sama dengan 73,36 sehingga diperoleh nilai Standar Deviasi sama dengan 6,775. Sedangkan pada variabel aggressive driving behavior diketahui nilai Minimum yang diperoleh sama dengan 59, nilai Maximum sama dengan 148, dengan Mean sebesar 116,56 sehingga dipeoleh nilai Standar Deviasi sebesar 11, 320.

Tabel 1. Data deskriptif penelitian

\begin{tabular}{llllll}
\hline & $N$ & $\begin{array}{l}\text { Xmi } \\
n\end{array}$ & $\begin{array}{l}\text { Xma } \\
x\end{array}$ & $\begin{array}{l}\text { Mea } \\
n\end{array}$ & $\begin{array}{l}\text { Standar } \\
\text { deviasi }\end{array}$ \\
\hline Regulasi emosi & 90 & 59 & 90 & 73,36 & 6.775 \\
& & & & & \\
Aggressive & 90 & 95 & 148 & $\begin{array}{l}116,5 \\
6\end{array}$ & $\begin{array}{l}11,32 \\
0\end{array}$ \\
driving behavior & & & & & \\
\hline
\end{tabular}

dapat $\begin{gathered}\text { Deskriptif data penelitian di atas } \\ \text { dijadikan dasar dalam }\end{gathered}$
pengkategorian sampel penelitian. Tujuan dari kategorisasi ini untuk menempatkan subjek kedalam kelompok-kelompok yang berjenjang, menurut rangkaian berdasarkan atribut yang diukur (Azwar, 2017).

Setelah diperoleh data deskriptif tersebut, maka selanjutnya peneliti melakukan pengkategorisasian pada masing-masing variabel. Sehingga pada variabel regulasi emosi ditemukan bahwa dari 90 subjek yang memiliki tingkat kategori regulasi emosi yang rendah adalah 14 subjek dengan persentase $15,56 \%, 60$ subjek masuk pada kategori sedang dengan persentase $66,67 \%$, dan 16 subjek dalam kategori tinggi dengan $17,77 \%$. Di bawah ini adalah tabel kategorisasi regulasi emosi.

Tabel 2. Kategorisasi regulasi emosi

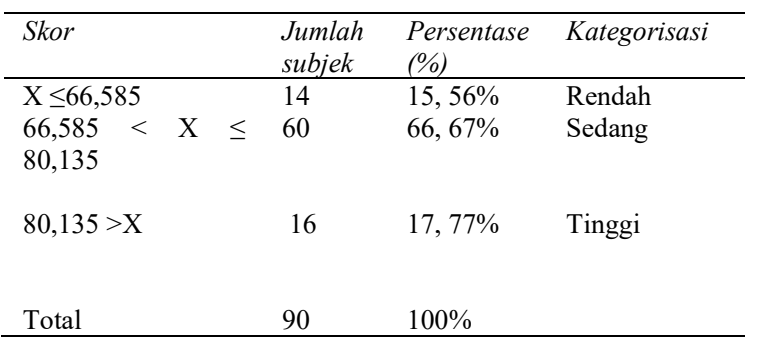

Sedangkan pada variabel aggressive driving behavior, dari 90 sampel penelitian, terdapat 17 subjek yang memiliki aggressive driving behavior rendah dengan persentase 17,78\%, 55 subjek berada pada kategori sedang dengan $62,22 \%$, dan 18 subjek berada pada kategori tinggi dengan perentase 20\%. Di 
bawah ini adalah tabel kategorisasi aggressive driving behavior.

Tabel 3. Kategorisasi aggressive driving behavior

\begin{tabular}{llll}
\hline Skor & $\begin{array}{l}\text { Jumlah } \\
\text { subjek }\end{array}$ & $\begin{array}{l}\text { Persentas } \\
e(\%)\end{array}$ & $\begin{array}{l}\text { Kategorisas } \\
i\end{array}$ \\
\hline $\mathrm{X} \leq 105,24$ & 17 & $17,78 \%$ & Rendah \\
$\begin{array}{l}105,24<\mathrm{X} \leq \\
127,88\end{array}$ & 55 & $62,22 \%$ & Sedang \\
$127,88>\mathrm{X}$ & 18 & $20 \%$ & Tinggi \\
Total & 90 & $100 \%$ & \\
\hline
\end{tabular}

Uji normalitas dilakukan untuk mengetahui apakah data yang diperoleh dari variabel yang diteliti berdistribusi normal atau tidak. Uji normalitas data menggunakan teknik One-Sample Kolmogorov-Smirnov dengan SPSS 20.0 for windows.

Hasil uji normalitas pada variabel regulasi emosi dan aggressive driving behavior menunjukkan nilai signifikansi pada variabel regulasi emosi sebesar 0,758 dan pada variabel aggressive driving behavior nilai signifikansi yang diperoleh adalah 0,813 . Nilai tersebut diketahui lebih besar dari $0,05(\mathrm{P} \geq 0,05)$. Hal ini menunjukkan bahwa data dari kedua variabel berdistribusi secara normal. Berikut adalah tabel hasil uji normalitas variabel regulasi emosi dan aggressive driving behavior.

Tabel 4. Uji normalitas

\begin{tabular}{lll}
\hline \multicolumn{3}{c}{ One-Sample Kolmogorov-Smirnov Test } \\
\hline & Signifikansi & Keterangan \\
Regulasi Emosi & 0,758 & $\mathrm{P} \geq 0,05$ (Normal) \\
Aggressive & 0,813 & $\mathrm{P} \geq 0,05$ (Normal) \\
Driving Behavior & & \\
& &
\end{tabular}

Uji linearitas bertujuan untuk mengetahui apakah kedua variabel yang akan diuji memiliki hubungan yang lurus (linear) atau tidak secara signifikan. Uji linearitas data menggunakan test for linearity pada program SPSS 20.0 for windows.
Hasil uji linearitas pada variabel regulasi emosi dan aggressive driving behavior menunjukkan nilai signifikansi deviation from linearity sebesar 1,276. Nilai ini lebih besar dari 0,05 ( $\mathrm{P} \geq 0,05)$, menunjukkan bahwa data variabel regulasi emosi dan aggressive driving behavior memiliki hubungan yang linear. Berikut adalah tabel hasil uji linearitas variabel regulasi emosi dan aggressive driving behavior.

Tabel 5. Uji linearitas

\begin{tabular}{lcl}
\hline Variabel & $\begin{array}{l}\text { Sig. deviation } \\
\text { from linearity }\end{array}$ & Keterangan \\
\hline Regulasi Emosi & 1.276 & Alat ukur (Linear) \\
$\begin{array}{l}\text { Aggressive } \\
\text { Driving Behavior }\end{array}$ & 1.276 & Alat ukur (Linear) \\
\hline
\end{tabular}

Setelah data penelitian dikatakan berdistribusi secara normal dan kedua variabel penelitian memiliki hubungan yang linear, peneliti melakukan uji hipotesis. Pengujian hipotesis dalam penelitian ini dilakukan menggunakan teknik korelasi Pearson product Moment dengan menggunakan bantuan SPSS 20.0 for windows.

Hasil data menunjukkan nilai signifikansi 0,000 . Nilai ini lebih kecil dari 0,01 sehingga dapat dikatakan bahwa terdapat hubungan antara regulasi emosi dan aggressive driving behavior, dengan nilai koefisien korelasi sebesar $0,464 * *$ yang bertanda positif menunjukkan bahwa adanya hubungan yang positif antara kedua variabel yang berada pada kategori sedang.

Tabel. 6 Uji korelasi

\begin{tabular}{lll}
\hline Variabel & Korelasi pearson & Sig. \\
\hline Regulasi Emosi & $0,464^{* *}$ & 0,000 \\
$\begin{array}{l}\text { Aggressive Driving } \\
\text { Behavior }\end{array}$ & $0,464 *$ & 0,000 \\
\hline
\end{tabular}

Penelitian ini dilakukan dengan tujuan untuk mengetahui apakah ada hubungan negatif antara regulasi emosi 
dan aggressive driving behavior pada siswa SMK Negeri 2 Kendari. Berdasarkan hasil uji korelasi antara regulasi emosi dan aggressive driving behavior menunjukkan bahwa ada hubungan positif yang signifikan antara kedua variabel yang artinya semakin tinggi regulasi emosi maka semakin tinggi aggressive driving behavior pada siswa SMK Negeri 2 Kendari, dan sebaliknya semakin rendah regulasi emosi maka semakin rendah pula aggressive driving behavior pada siswa SMK Negeri 2 Kendari.

Berdasarkan pengkategorian yang telah dilakukan sebelumnya, tingkat hubungan regulasi emosi terhadap aggressive driving behavior pada siswa SMK Negeri 2 Kendari dapat dijelaskan sebagai berikut, terdapat 2 siswa yang memiliki regulasi emosi tinggi, ternyata juga memiliki aggressive driving behavior yang rendah dan 1 siswa yang memiliki regulasi emosi rendah, juga memiliki aggressive driving behavior yang tinggi. Pengemudi yang berperilaku agresif saat berkendara berada di bawah pengaruh emosi yang tidak stabil sehingga menghasilkan perilaku yang beresiko dan berakibat buruk bagi dirinya dan pengguna jalan lain, sebaliknya pengendara yang memiliki kemampuan mengatur emosi akan mengemudi dengan hati-hati.

Data lain ditemukan pada 10 siswa yang memiliki regulasi emosi tinggi, juga memiliki aggressive driving behavior yang tinggi pula. Sebanyak 44 siswa memiliki regulasi emosi sedang, juga memiliki aggressive driving behavior yang sedang, dan sebanyak 6 siswa memiliki regulasi emosi rendah juga memiliki aggressive driving behavior yang rendah. Untuk lebih jelasnya di bawah ini terdapat tabel yang menunjukkan tingkat hubungan regulasi emosi dan aggressive driving behavior berdasarkan kategorisasi.
Tabel 7. Hubungan regulasi emosi dan aggressive driving behavior berdasarkan kategorisasi

\begin{tabular}{|c|c|c|c|c|}
\hline \multirow{2}{*}{ Regulasi Emosi } & \multicolumn{3}{|c|}{ Aggressive Driving Behavior } & \multirow[t]{2}{*}{ Total } \\
\hline & Tinggi & Sedang & Rendah & \\
\hline Tinggi & 10 & 4 & 2 & 16 \\
\hline Sedang & 7 & 44 & 9 & 60 \\
\hline Rendah & 1 & 7 & 6 & 14 \\
\hline Total & 18 & 55 & 17 & 90 \\
\hline
\end{tabular}

Dari hasil tersebut, maka dapat disimpulkan bahwa siswa yang memiliki regulasi emosi yang baik tidak selalu berada dalam kondisi stabil. Menurut Gross dan Thompson (2007) dalam proses meregulasi emosi, bentuk emosi yang dirasakan individu dapat ditingkatkan, dikurangi, atau dipertahankan. Dengan demikian siswa yang mampu meregulasi emosinya saat mengendara bisa saja melakukan perilaku agresif atau aggressive driving behavior.

Menurut Gross \& Thompson, 2007 terdapat dua strategi dalam meregulasi emosi, yaitu strategi regulasi emosi yang berpusat pada antaseden dan strategi regulasi emosi yang berpusat pada respon. Subjek yang memiliki regulasi emosi yang baik tetapi juga melakukan aggressive driving behavior menggunakan strategi regulasi emosi yang berfokus pada anteseden yaitu strategi regulasi emosi yang dilakukan sebelum adanya penilaian atau respon terhadap emosi (Gross \& Thompson, 2007). Anteseden merupakan stimulus yang memberi syarat pada individu untuk melakukan perilaku yang dipelajari. Saat mempelajari perilaku tersebut, individu dapat menilai situasi yang terjadi pada individu lain sehingga individu yang bersangkutan mampu mengubah emosi secara signifikan. Misalnya individu yang memikirkan tentang kapasitas yang dimiliki mampu untuk menangani tuntutan-tuntutan dari respon emosi tersebut. Dengan demikian siswa yang merasa mampu dan memiliki kapasitas atau merasa dirinya superior 
dengan mudah akan melakukan perilaku agresif saat mengendara di jalan raya atau aggressive driving behavior.

Selain uraian yang telah dijelaskan di atas, tidak adanya hubungan antara regulasi emosi dan aggressive driving behavior pada siswa SMK Negeri 2 Kendari juga dapat dipengaruhi oleh faktor internal dan faktor eksternal. Menurut Tasca (Prasetyo \& Septiningsih, 2011) faktor eksternal yang dapat mempengaruhi aggressive driving behavior diantaranya adalah anonimitas, faktor sosial, dan faktor lingkungan. Banyak kasus aggressive driving yang tidak mendapatkan hukuman dapat membentuk persepsi bahwa perilaku seperti ini adalah normal dan dapat diterima, sehingga para pengemudi merasa bahwa perilaku aggressive driving yang dilakukannya tidak terkontrol oleh pihak yang berwajib.

Adapun faktor lain yang berkaitan "imaginary audiene syndrome". Elkind (Azhari, Dahlan \& Mustofa, 2019) imaginary audiene syndrome merupakan salah satu komponen dari egosentrisme remaja yang menyebabkan kegagalan remaja dalam membedakan perspektif dirinya dari orang lain. Remaja merasa kehadirannya diperhatikan dan semua aktivitasnya disadari oleh orang lain. Terjadinya imagery audience ditandai dengan adanya remaja mulai memikirkan bagaimana penilaian orang lain mengenai dirinya, penampilannya dan perilakunya. Dengan adanya perasaan tersebut, remaja selalu menampilkan diri yang positif dan merasa dirinya tidak mempunyai masalah.

Salah satu dari dimensi imagery audience adalah self-focusing appearance, yakni remaja selalu memperhatikan dengan detail penampilannya demi menghindari kritik-kritik orang lain. Hal ini terlihat pada saat pengisian skala, siswa SMK Negeri 2 Kendari melakukan imaginary audiene untuk menunjukkan bahwa subjek tidak mempunyai masalah dan subjek ingin menampilkan hal-hal baik dari dirinya agar menghindari kritikan negatif dari orang lain mengenai dirinya.
Selain itu, karakteristik siswa SMK Negeri

2 Kendari yang tergolong dalam usia remaja juga memiliki kebutuhan akan mempertahankan rasa diri positif, sehingga mengalami kesulitan dalam penilaian diri sendiri (self-assessment). Siswa yang terlalu sering mempertahankan rasa diri yang positif dan imaginary audiene akan melakukan penilaian diri yang tidak akurat. Observasi diri yang akurat ditutupi oleh kekhawatiran siswa akan pandangan orang lain tentang diri mereka sehingga mereka cenderung mempersepsikan diri mereka tidak mempunyai masalah.

\section{Kesimpulan}

Berdasarkan hasil penelitian yang dilakukan pada siswa SMK Negeri 2 Kendari terkait dengan hubungan antara regulasi emosi dan aggressive driving behavior pada siswa SMK Negeri 2 Kendari, hasil yang didapatkan adalah terdapat hubungan positif yang signifikan antara regulasi emosi dan aggressive driving behavior siswa SMK Negeri 2 Kendari. Hal ini berarti bahwa semakin tinggi regulasi emosi maka semakin tinggi pula aggressive driving behaviors pada siswa SMK Negeri 2 Kendari, sebaliknya semakin rendah regulasi emosi maka semakin rendah pula aggressive driving behavior pada siswa SMK Negeri 2 Kendari.

Agar dapat mencegah dan mengurangi dampak negatif pada para pengguna jalan raya baik pengendara maupun pejalan kaki, maka peneliti menyarankan kepada peneliti selanjutnya agar mengkaji lebih lanjut faktor-faktor yang dapat mempengaruhi aggressive driving behavior baik pada remaja, maupun orang dewasa. Peneliti selanjutnya juga dapat menggunakan variabel lain yang tidak dijelaskan dalam penelitian ini misalnya, kontrol diri, kematangan emosi, konsep diri, kepribadian, konformitas, gaya hidup, ataupun kelompok sosial. Bagi peneliti selanjutnya disarankan juga agar dapat menggunakan sampel yang lebih luas lagi misalnya pengendara/sopir 
angkut, pengemudi taxi online, ojek/ojol atau grab dengan pengendara wanita.

\section{Daftar Pustaka}

Anggar, S. (2017). Tujuh puluh dua persen kecelakaan lalu lintas dialami sepeda motor. Diunduh dari: https://amp.kontan.co.id/news/72kecelakaan-lalu-lintas-dialamisepeda-motor.

Ambarwati, L., Sulistio, H., Negara. G. H., \& Heriadi, Z. (2010). Karakteristik dan peluang kecelakaan pada mobil pribadi di wilayah perkotaan. Jurnal Rekayasa Sipil. 4(2), 124135.

Arnau-Sabates, L., Sala-Roca, J., \& JariotGarcia, M. (2012). Emotional abilities as predictors of risky driving behavior among a cohort of middleaged drivers. Accident Analysis \& Prevention, 45: 818825.

Azhari, S.M., Dahlan, T. H., \& Mustofa, M. A. (2019). Imagery Audience, Personal Fable, dan perilaku agresi remaja. Jurnal Psikologi Insight. $3(2), 32-42$.

Azwar. (2017). Metode Penelitian Psikologi. Yogyakarta: Pustaka Pelajar.

Gross, J. J. \& Thompson, R. A. (2007). Emotional regulation: Conceptual Foundation. Handbook of emotion regulation, edited by James J. Gross. New York: Guilfors Publication.

Haleem, K., \& Gan, A. (2015). Contributing factors of crash injury seventy at public highway-railroad grade crossing in the U.S. Journal Of Safety Research 53(1), 23-29.

Harris, P. B., Houston, J. M., Vazquez, J. A., Smither, J. A., \& Harms, A.
(2014). The prosocial aggressive driving inventory (PADI): A selfreport measure of safe and unsafe driving behaviors. Department of Psychology Rollins Collage. 1-29.

Herani, I. \& Jauhari A. K., (2017). Perilaku berkendara agresif para pengguna kendaraan bermotor di Kota Malang. Mediapsi. 3(2), 2938.

Hidayati. (2015). Hubungan Jenis Kelamin dan Faktor Perilaku Pengemudi sepeda motor dengan kecelakaan lalu lintas di Kecamatan monokromo, Surabaya pada Siswa SMP Tahun 2015. Skripsi. Tidak Diterbitkan. Surabaya: Universitas Airlangga.

Holland, C., Geraghty, J., \& Shah, K. (2010). Differential moderating effect of locus of control on effect of driving experience in young male and female drivers. The Journal Personality and Individual Differences. 48, 821-826.

Ibraheim, M., Kalpakci, A., \& Sharp. (2017). The specifiaty of emotion dysregulation in adolescents with borderline personality disorder: comparison with psyciatri and healthy controls. Borderline Personality Disorder and Emotional Dysregulation. 4(1), 19.

Kustiyah, N. (2011). Pengaruh perilaku pengemudi sepeda motor dan lingkungan terhadap kejadian kecelakaan lalu lintas di Kabupaten Sidoarjo tahun 2010. Skripsi. Tidak Diterbitkan. Surabaya: Universitas Airlangga.

Notosiswoyo, M. (2014). Pengetahuan, sikap, dan perilaku siswa SLTA dalam pencegahan kecelakaan sepeda motor di Kota Bekasi. 
Jurnal Ekologi Kesehatan. 13(1), 1-9.

Permanawati, T., Sulistio, H., \& Wicaksono. (2010). Model peluang kecelakaan sepeda motor berdasarkan karakteristik pengendara. Jurnal Rekayasa Sipil. 4(3), 185-194.

Prasetyo, W. E., \& Septiningsih, D. S. (2011). Studi deskriptif tentang aggressive driving sepeda motor $\mathrm{di}$ jalan raya pada peserta didik Sekolah Menengah Kejuruan (SMK) Muhammadiyah 2 Ajibarang. Psycho Idea. 9(2), 3746.

Rakhmani, F. (2013). Kepatuhan Remaja dalam Berlalu Lintas. Jurnal S-1 Ilmu Sosiatri. 2(1), 1-7.

Santrock, J. W. (2011). Adolescence: Perkembangan Remaja (ed.6). Jakarta: Erlangga.

Soffania, M. I. (2018). Hubungan aggressive driving pengemudi sepeda motor dengan kecelakaan lalu lintas (Studi Pada Siswa SMA di Kabupaten Sidoarjo). IJPH. 1020473. 220-23.

Swadnyana, I. P. A., \& Tobing, D. H. (2019). Hubungan Antara Kecerdasan Emosional dan agresivitas Pada Remaja di SMA Dwijendra Denpasar. Jurnal Psikologi Udayana. 6(1), 120-129.

Trogolo, M. A., Melchior, F., \& Medrano, L.A. (2014). The role of difficulties in emotion regulation on driving behavior. Journal of Behavior, Health \& sicoal Issues. 6(1), 1071176.
Utari. (2016). Hubungan aggressive driving dan kematangan emosi dengan disiplin berlalu lintas pada pengendara sepeda motor di Samarinda. eJournal Psikologi. 4(3), 352-360.

World Health Organization. (2013). Global status report on road safety 2013 (supporting adcade of action). (1). 